\title{
Resiliensi Trauma Pada Dewasa Muda Penyintas Kekerasan Yang Terindikasi Posttraumatic Stress Disorder (PTSD)
}

\author{
Chandradewi Kusristanti ${ }^{1}$, Arif Triman ${ }^{2}$, Renada Gita Paramitha ${ }^{3}$ \\ ${ }^{1}$ Fakultas Psikologi \\ Universitas YARSI \\ 11chandradewi.kusristanti@yarsi.ac.id/ chandradewi.k@gmail.com
}

\begin{abstract}
Violence is categorized as a traumatic experience for its survivors. Although violent incidents can increase the risk of developing PTSD (post-traumatic stress disorder), several works of literature showed that some people can adapt positively. We argued that trauma resilience is a factor that significantly correlated with PTSD symptoms found in violence survivors. This study is aimed to investigate the association between trauma resilience and PTSD symptoms among violence survivors. Measurements used in this study are Trauma Resilience Scale $(\alpha=0.956)$ which was constructed by Madsen and Abell (2010) and PTSD Checklist-Civilian Version $(\alpha=0.709)$. We recruited participants through purposive sampling ( $\mathrm{n}=$ 75 ), with participants' characteristics are individuals who experienced violence, age 20 - 40 years old, and scored $\geq 50$ in PTSD Checklist-Civilian Version to indicate they indeed develop some PTSD symptoms. Data were analysed using Spearman's Rank on JASP 0.8.6.0. The result showed that trauma resilience and PTSD symptoms among participants are significantly correlated $(p<0.01 ; r s=-0.637)$. Result of this study indicates the need to establish a group counseling or training program that focused on enhancing resilience designed for people with a history of violence.
\end{abstract}

Keyword : PTSD, resilience, Trauma Resilience Scale (TRS), violence

\begin{abstract}
Abstrak
Kekerasan merupakan pengalaman traumatik bagi penyintasnya. Meskipun peristiwa kekerasan dapat meningkatkan risiko untuk mengembangkan PTSD (post-traumatic stress disorder), namun ada beberapa individu yang tetap mampu beradaptasi positif. Peneliti berpendapat bahwa resiliensi trauma merupakan salah satu faktor yang berkorelasi signifikan dengan simtom PTSD yang dialami oleh penyintas kekerasan. Penelitian ini bertujuan untuk mengetahui hubungan antara resiliensi trauma dan simtom PTSD pada partisipan berupa penyintas kekerasan. Penelitian ini menggunakan alat ukur Trauma Resilience Scale $(\alpha=0.956)$ yang dikonstruksi oleh Madsen dan Abell (2010) untuk mengukur resiliensi trauma dan alat ukur PTSD Checklist-Civilian Version $(\alpha=0.709)$ untuk mengukur simtom PTSD pada partisipan. Dengan menggunakan purposive sampling, terdapat 75 orang partisipan penelitian yang memenuhi kriteria penelitian, yaitu individu yang mengalami kekerasan berusia 20-40 tahun dan mencapai skor $\geq 50$ pada alat ukur
\end{abstract}


PTSD Checklist-Civilian Version untuk mengindikasikan adanya simtom PTSD. Data kemudian diolah menggunakan analisis Spearman's Rank dengan menggunakan software statistik JASP 0.8.6.0, dan ditemukan bahwa kedua variabel berkorelasi signifikan $\left(\mathrm{p}<0.01 ; \mathrm{r}_{\mathrm{s}}=-0.637\right)$. Temuan ini mengindikasikan kebutuhan untuk menciptakan program konseling kelompok ataupun pelatihan yang secara spesifik didesain untuk individu dengan pengalaman kekerasan.

Kata kunci: PTSD, resiliensi, Trauma Resilience Scale (TRS), kekerasan 


\section{Pendahuluan}

Kekerasan merupakan fenomena yang menjadi perhatian dunia. Dalam laporan global mengenai kekerasan dan kesehatan yang dirilis oleh World Health Organization (WHO) tahun 2002 lalu, kekerasan merupakan salah satu dari penyebab utama kematian di dunia untuk individu usia 15 - 44 tahun. Madsen dan Abell (2010) mengklasifikasikan kekerasan ke dalam empat jenis, yaitu: kekerasan domestik, kekerasan seksual/ pemerkosaan, kekerasan fisik/ penganiayaan, dan kejadian lainnya yang mengancam hidup. Sejumlah literatur menunjukkan bahwa peristiwa kekerasan memiliki dampak yang bervariasi bagi individu, salah satunya adalah trauma.

Secara umum, trauma didefinisikan sebagai kejadian-kejadian menekan yang memberikan tantangan luar biasa untuk coping dan adaptasi (Agaibi \& Wilson, 2005). Suatu survey epidemiologis yang dilakukan oleh WHO terhadap partisipan di 24 negara menemukan bahwa trauma akibat tipe kekerasan yang satu akan berbeda dengan yang diakibatkan oleh tipe kekerasan lainnya, serta berdampak pada risiko kemunculan PTSD (posttraumatic stress disorder) pada penyintas (Kessler, dkk., 2017). Sejumlah penelitian menemukan bahwa PTSD lazim ditemukan pada kekerasan dalam konteks relasi intim (e.g. Babcock, Roseman, Green, \& Ross, 2008; Amar \& Otálvaro, 2012) ataupun konteks relasi yang lebih luas (e.g. Gillikin, Habib, Evces, Bradley, Ressler, \& Sanders, 2016).

Secara umum, PTSD merupakan sindrom yang mencakup dua komponen esensial, yaitu timbul sebagai akibat dari kejadian traumatis dan merupakan konstelasi dari sejumlah simtom, di antaranya mengalami kembali (reexperiencing), penghindaran (avoidance), mati rasa (numbing), dan gairah yang berlebihan (hyperarousal) (Ehrenreich, 2003). Simtom-simtom tersebut bertahan selama 6 bulan agar diagnosis PTSD bisa ditegakkan. Simtom-simtom tersebut dapat mempengaruhi identitas diri individu dan dapat melibatkan perasaanperasaan seperti 'jijik' pada diri sendiri, merasa gagal, harga diri rendah, dan bahkan pada beberapa kasus ekstrem dapat berujung pada pemikiran tentang bunuh diri (Wilson, Drozdek, \& Turkovic, dalam Ellison \& Munro, 2017).

Sejumlah studi menunjukkan bahwa korban kekerasan merupakan suatu kelompok yang rentan mengalami PTSD. Dengan menggunakan metode 
wawancara diagnostik, studi yang dilakukan oleh Nathanson, Shorey, Tirone, dan Rhatigan (2012) terhadap wanita yang menjadi korban kekerasan dalam relasi intim menemukan bahwa sebagian besar partisipan memenuhi kriteria diagnostik terkait gangguan kesehatan mental, di mana PTSD menjadi gangguan kesehatan mental yang paling lazim ditemukan. Penelitian tersebut juga menemukan bahwa kekerasan psikologis yang dialami partisipan menjadi prediktor signifikan bagi PTSD dan juga depresi. Kekerasan berupa pemerkosaan ataupun pelecehan seksual lainnya juga dapat berdampak terhadap timbulnya PTSD pada korban. Hal tersebut salah satunya ditunjukkan dari hasil penelitian yang dilakukan oleh Creamer, Burgess, dan McFarlane (2001), yang menemukan bahwa prevalensi PTSD ditemukan pada 50\% wanita korban kekerasan seksual. Jenis kekerasan lain yaitu penganiayaan fisik juga dapat menimbulkan PTSD pada korbannya, seperti ditunjukkan dalam penelitian yang dilakukan oleh Schnell, Marshall, dan Jaycox (2004, dalam Hyland, Shevlin, Hansen, Vallières, Murphy \& Elklit, 2016) serta penelitian Schell, Glynn, dan Shetty (2006, dalam Hyland, dkk., 2016). Kedua penelitian longitudinal tersebut menemukan bahwa partisipan penelitian masih terus mengalami simtom arousal, yang merupakan prediktor terkuat setiap kluster simtom PTSD, dan bertahan hingga 12 bulan setelah asesmen dilakukan.

Di sisi lain, sejumlah penelitian menemukan bahwa tidak seluruh individu yang mengalami peristiwa traumatis mengalami dampak negatif. Resiliensi merupakan salah satu faktor protektif yang dapat membantu individu menghadapi peristiwa traumatis. Resiliensi merupakan kemampuan individu yang mengalami kejadian yang sangat mengganggu, salah satunya kekerasan, untuk mempertahankan fungsi psikologis dan fisik yang relatif stabil (Bonanno, 2004). Madsen dan Abell (2010) mengonseptualisasikan resiliensi dalam konteks trauma kekerasan sebagai suatu fenomena yang menguatkan individu untuk kembali berfungsi setelah mengalami kejadian traumatis berupa kekerasan.

Dalam beberapa waktu terakhir, resiliensi menjadi salah satu topik yang paling diminati, dan resiliensi sekarang dikenal sebagai salah satu faktor yang paling penting untuk menilai penyesuaian yang sehat dan patologis pada individu yang mengalami trauma (Lyons, dalam Connor, 2006). Lebih jauh lagi, sejumlah penelitian mengemukakan bahwa signifikansi klinis dari resiliensi terletak pada 
keberfungsiannya sebagai indeks dari kesehatan mental secara keseluruhan (Maddi \& Khoshaba, 1994; Ramanaiah, Sharpe, \& Byravan, 1999, dalam Connor, 2006). Madsen dan Abell (2010) menekankan pentingnya investigasi mengenai faktorfaktor protektif terkait kekerasan, terlebih karena belum banyaknya tes yang reliabel dalam menguji konsep tersebut. Madsen dan Abell (2010) kemudian mengembangkan suatu alat ukur yang bertujuan untuk menilai faktor-faktor protektif bagi individu yang pernah mengalami kekerasan, yang terdiri dari domain relasi suportif (supportive relationship), optimisme, pemecahan masalah, dan spiritualitas.

Salah satu yang menjadi karakteristik dari kekerasan adalah manifestasi dampak yang dapat terjadi langsung setelah kejadian, ataupun terjadi jauh setelah peristiwa kekerasan tersebut terjadi. Sejumlah studi menemukan bahwa anak-anak yang pernah mengalami kekerasan seksual memiliki kecenderungan untuk terlibat dalam tindak kriminal yang melibatkan seks di kemudian hari (Smith \& Thornberry, 1995; Zingraff, Leiter, Myers, \& Johnsen, 1993). Sementara itu, pada individu berusia dewasa awal, dampak kekerasan dapat dimanifestasikan pada sejumlah perilaku berisiko, seperti merokok, minum minuman keras, ataupun menggunakan obat-obatan terlarang (Papalia \& Feldman, 2014). Dengan demikian, peneliti meyakini bahwa melakukan penelitian pada penyintas kekerasan yang berusia dewasa muda menjadi penting untuk dilakukan.

Mengacu pada paparan di atas, peneliti merumuskan pertanyaan penelitian berupa "Apakah terdapat hubungan yang signifikan antara gejala PTSD dan resiliensi trauma pada penyintas kekerasan berusia dewasa muda?". Penelitian ini memiliki hipotesis berupa adanya hubungan yang signifikan antara gejala PTSD dan resiliensi trauma pada partisipan. Hasil penelitian ini diharapkan dapat memberikan informasi tambahan mengenai kondisi psikologis penyintas kekerasan di Indonesia, terutama yang terkait dengan PTSD. 


\section{Metode}

\section{Tipe dan Desain Penelitian}

Penelitian ini menggunakan metode kuantitatif dengan desain korelasional. Menurut Kumar (2011), suatu penelitian diklasifikasikan sebagai penelitian kuantitatif apabila fenomena yang diteliti dijelaskan melalui kuantifikasi data. Dalam penelitian ini, data yang diperoleh dari partisipan akan dikuantifikasi dengan menggunakan analisis statistik. Sementara itu, Kumar (2011) menyatakan bahwa penelitian dengan desain korelasional bertujuan untuk menemukan hubungan atau asosiasi antara dua atau lebih variabel. Penelitian ini bertujuan untuk menemukan hubungan antara gejala PTSD dan resiliensi trauma.

\section{Alat Ukur}

Peneliti menggunakan alat ukur berupa kuesioner, salah satunya adalah PTSD Checklist-Civilian Version (PCL-C) untuk mengukur gejala PTSD partisipan. Alat ukur ini disusun berdasarkan diagnosis PTSD menurut Diagnostic and Statistical Manual of Mental Disorders-IV-TR (DSM-IV-TR). Alat ukur ini telah banyak digunakan untuk mengukur PTSD pada berbagai sampel, dan telah diadaptasi di beberapa negara. Alat ukur ini terdiri dari 17 aitem yang seluruhnya dinilai secara favorable. Skala dalam alat ukur ini merupakan skala Likert $(1-5)$. Gejala PTSD dapat dilihat dari skor total individu pada alat ukur ini. Skor $\geq 50$ mengindikasikan gejala PTSD pada partisipan (Weathers, Litz, Herman, dan Keane, 1993). Dengan menggunakan teknik Alpha Cronbach, hasil uji coba menunjukkan bahwa alat ukur ini reliabel untuk digunakan $(\alpha>0.709)$.

Alat ukur berikutnya adalah Trauma Resilience Scale (TRS), yang digunakan untuk mengukur resiliensi trauma pada partisipan. TRS merupakan alat ukur resiliensi yang dikonstruksi dengan sampel berupa penyintas kekerasan oleh Madsen dan Abell (2010). Alat ukur ini terdiri dari 4 domain, yaitu dukungan yang mendukung, optimisme, pemecahan masalah, dan spiritualitas. Total aitem pada alat ukur ini adalah 48, yang terdiri dari 38 aitem favorable dan 10 aitem unfavorable. Skala dalam alat ukur ini adalah skala Likert (1-7). Resiliensi trauma partisipan dapat dilihat dari skor rata-rata individu pada alat ukur ini. Dengan 
menggunakan teknik Alpha Cronbach, alat ukur ini diketahui reliabel untuk digunakan $(\alpha>0.956)$.

Selain kedua alat ukur tersebut, peneliti juga menyertakan kuesioner mengenai demografi partisipan serta data terkait kekerasan yang partisipan alami. Kuesioner tersebut peneliti susun berdasarkan tinjauan literatur mengenai kekerasan. Aitem-aitem pada kuesioner tersebut meliputi frekuensi kekerasan, pelaku kekerasan, dan lain sebagainya.

\section{Sampel}

Karakteristik sampel pada penelitian ini adalah individu berusia dewasa muda (20 - 40 tahun) yang pernah mengalami kekerasan $(n=75)$. Kekerasan yang dimaksud adalah kekerasan yang dikategorikan oleh Madsen dan Abell (2010), yaitu kekerasan dalam rumah tangga, kekerasan seksual/ pemerkosaan, kekerasan fisik, serta kekerasan atau kejadian lainnya yang mengancam nyawa. Pemilihan sampel pada penelitian ini menggunakan metode purposive sampling.

Sebelum mengisi kuesioner, seluruh partisipan telah menandatangani informed consent yang menyatakan kesediaan mereka mengikuti penelitian ini. Pada awalnya, terdapat 171 partisipan yang mengisi alat ukur pada penelitian ini. Peneliti kemudian melakukan screening gejala PTSD menggunakan alat ukur PCL-C dengan ketentuan partisipan yang mendapatkan skor $\leq 50$ tidak terindikasi memiliki gejala PTSD. Setelah proses screening partisipan tersebut, terdapat 75 orang partisipan yang mengalami gejala PTSD. Data dari 75 partisipan tersebut kemudian diolah oleh peneliti.

\section{Teknik Statistik}

Pada tahap pertama, data diolah menggunakan uji normalitas KolmogorovSmirnov untuk melihat persebaran data. Dari hasil uji normalitas tersebut, ditemukan bahwa data tidak terdistribusi normal. Dengan demikian, pengolahan data berupa uji korelasi dilakukan dengan menggunakan teknik Spearman's Rank. Selanjutnya, untuk memperkaya hasil penelitian, peneliti juga melakukan uji beda pada data demografi dengan menggunakan t-test dan Mann-Whitney. Seluruh 
pengolahan data tersebut dilakukan dengan menggunakan software statistik JASP 0.8.6.0.

\section{Hasil Penelitian}

Tabel 1 di bawah ini memuat persebaran data demografi dari 75 orang partisipan:

Tabel 1

Data Demografi

\begin{tabular}{ccc}
\hline Variabel/ Kategori & n & $\%$ \\
\hline Jenis Kelamin & & \\
Laki-Laki & 32 & $42.7 \%$ \\
Perempuan & 43 & $57.3 \%$ \\
\hline
\end{tabular}

\section{Usia}

\begin{tabular}{lll}
$\begin{array}{l}\text { 20-29 tahun } \\
\text { 30-40 tahun }\end{array}$ & 45 & $60 \%$ \\
\hline $\begin{array}{l}\text { Pendidikan } \\
\text { Tinggi }\end{array}$ & $40 \%$ \\
$\quad$ Dasar & 39 & $52 \%$ \\
\hline $\begin{array}{l}\text { Status Pernikahan } \\
\text { Belum menikah/ } \\
\text { Bercerai }\end{array}$ & 30 & $48 \%$ \\
\hline Menikah & 45 & $60 \%$ \\
\hline
\end{tabular}

Frekuensi Kekerasan

\begin{tabular}{ccc}
1 kali & 8 & $10.7 \%$ \\
$>1$ kali & 67 & $89.3 \%$ \\
\hline Pelaku Kekerasan & & \\
Dikenal & 71 & $94.7 \%$ \\
Tidak dikenal & 4 & $5.3 \%$ \\
\hline
\end{tabular}




\section{Durasi Kekerasan}

\begin{tabular}{lcc}
\multicolumn{1}{l}{$\begin{array}{l}\text { 1 tahun } \\
>1 \text { tahun }\end{array}$} & 49 & $65.3 \%$ \\
\hline $\begin{array}{l}\text { Keberlangsungan } \\
\text { Kekerasan } \\
\quad \text { Telah berakhir }\end{array}$ & 57 & $34.7 \%$ \\
$\quad \begin{array}{l}\text { Masih berlangsung } \\
\text { Akses terhadap }\end{array}$ & 18 & $24 \%$ \\
$\begin{array}{l}\text { Treatment } \\
\text { Mengakses }\end{array}$ & 10 & $13.3 \%$ \\
$\quad$ Tidak mengakses & 65 & $86.7 \%$ \\
\hline
\end{tabular}

Dari data yang ditampilkan dalam tabel 1, dapat disimpulkan bahwa sebagian besar partisipan penelitian ini berjenis kelamin wanita (57.3\%), berusia 20-29 tahun (60\%), melanjutkan pendidikan tinggi berupa Diploma hingga Magister (52\%), dan berstatus menikah (60\%). Terkait peristiwa kekerasan yang dialami, sebagian besar dari mereka mengalami kekerasan sebanyak lebih dari satu kali (89.3\%), dengan pelaku berupa orang yang dikenal $(94.7 \%)$ dan kekerasan tersebut berlangsung kurang dari setahun (65.3\%). Meskipun sebagian besar partisipan sudah tidak lagi mengalami peristiwa kekerasan (76\%), hanya saja mayoritas partisipan tidak mengakses treatment medis ataupun psikologis untuk mengatasi dampak dari kekerasan yang dialami (86.7\%).

Sebelum melakukan uji korelasi untuk pengujian hipotesis, peneliti melakukan uji normalitas untuk melihat apakah data terdistribusi normal pada kedua variabel penelitian. Hasil perhitungan dengan metode Kolgomorov-Smirnov menunjukkan bahwa data variabel resiliensi trauma terdistribusi normal (KS Z $=0.109, p>0.05$ ), sedangkan data variabel PTSD tidak terdistribusi normal (KS $\mathrm{Z}=0.153, p<0.05)$. Oleh karena itu, uji korelasi yang digunakan dalam penelitian ini menggunakan Spearman's Rank.

Setelah dilakukan pengujian korelasi, ditemukan bahwa terdapat hubungan yang signifikan antara resiliensi trauma dengan gejala PTSD pada individu yang 
pernah mengalami kekerasan $\left(p<0.01 ; \mathrm{r}_{\mathrm{s}}=-0.637\right.$,). Dengan kata lain, hipotesis penelitian ini diterima. Berdasarkan nilai $\mathrm{r}_{\mathrm{s}}$, dapat disimpulkan adanya hubungan negatif yang cukup kuat antara resiliensi trauma dan gejala PTSD pada individu yang pernah mengalami kekerasan.

Untuk memperkaya hasil penelitian, peneliti turut melakukan uji beda pada kedua variabel penelitian berdasarkan faktor demografi dengan menggunakan Mann-Whitney ataupun $t$-test. Berdasarkan hasil uji beda tersebut, hanya beberapa faktor demografis yang menunjukkan perbedaan signifikan. Hasil uji beda yang signifikan adalah perbedaan resiliensi trauma berdasarkan usia maupun status pernikahan partisipan dan perbedaan gejala PTSD berdasarkan keberlangsungan kekerasan yang dialami partisipan. Dengan kata lain, tidak ada perbedaan yang signifikan pada data demografi lainnya, baik terkait PTSD ataupun resiliensi trauma. Hasil uji beda tersebut ditampilkan pada Tabel 2 di bawah ini:

Tabel 2

Hasil Uji Beda

\begin{tabular}{ccc}
\hline Data Demografi & Gejala PTSD & \multicolumn{1}{c}{$\begin{array}{c}\text { Resiliensi } \\
\text { Trauma }\end{array}$} \\
\hline Jenis Kelamin & 0.74 & 0.15 \\
\cline { 2 - 3 } Pendidikan & 0.06 & 0.62 \\
\cline { 2 - 3 } Status Pernikahan & 82 & $\begin{array}{l}0.012 \\
* *\end{array}$ \\
\cline { 2 - 3 } Usia & 0.47 & $\begin{array}{l}0.02 \\
* *\end{array}$ \\
\cline { 2 - 3 } Frekuensi Terpapar Kekerasan & 0.18 & 0.63 \\
\hline Pelaku Kekerasan & 0.78 & 0.86 \\
\hline $\begin{array}{c}\text { Keberlangsungan } \\
\text { Kekerasan } \\
\text { Trearment }\end{array}$ & $\begin{array}{l}0.04 \\
* *\end{array}$ & 0.10 \\
\cline { 2 - 3 } & 0.52 & 193
\end{tabular}

Usia partisipan merupakan salah satu variabel yang menunjukkan perbedaan signifikan. Jika dilihat dari perbedaan usia, terdapat perbedaan resiliensi trauma yang signifikan antara kelompok partisipan berusia 20-29 tahun dengan partisipan 
dalam kelompok usia 30-40 tahun $(\mathrm{t}=2.31, p<0.05)$. Secara lebih detil, tingkat resiliensi trauma lebih tinggi ditemukan pada partisipan yang berusia 20-29 tahun ( mean=178.7) dibandingkan partisipan berusia 30-40 tahun (mean=156.1).

Perbedaan signifikan berikutnya ditemukan pada variabel demografi berupa status pernikahan, yang juga mengindikasikan keberadaan pasangan dari partisipan. Hasil uji beda tersebut menunjukkan adanya perbedaan yang signifikan antara kelompok partisipan yang belum menikah atau bercerai dengan kelompok partisipan yang menikah $(\mathrm{t}=-2.57, p<0.05)$. Partisipan yang menikah menunjukkan resiliensi trauma yang lebih tinggi (mean=179.6) dibandingkan dengan partisipan yang belum menikah atau bercerai (mean=154.7).

Sementara itu, variabel keberlangsungan kekerasan menjadi satu-satunya faktor demografi yang memiliki perbedaan signifikan terkait gejala PTSD yang dilaporkan partisipan $(\mathrm{t}=-2.02, p<0.05)$. Lebih jauh lagi, hasil uji beda menunjukkan bahwa partisipan yang masih mengalami kekerasan melaporkan gejala PTSD yang lebih kuat (mean=67.8) dibandingkan partisipan yang sudah tidak mengalami kekerasan (mean=64.2).

\section{Pembahasan}

Hasil penelitian ini menunjukkan bahwa resiliensi trauma berkorelasi negatif secara signifikan dengan gejala PTSD pada partisipan. Dengan kata lain, semakin partisipan memiliki resiliensi terhadap trauma, semakin rendah pula tingkat PTSD yang dialami. Secara umum, hasil penelitian ini sejalan dengan hasil penelitian-penelitian lain yang meneliti tentang resiliensi pada partisipan yang mengalami trauma. Resiliensi diketahui merupakan faktor yang mendukung kesehatan mental secara umum (Haddadi \& Besharat, 2010), dan secara spesifik resiliensi berperan sebagai faktor protektif terkait PTSD (Ssenyonga, Owens, \& Olema, 2013; Wrenn, Wingo, Moore, Pelletier, Gutman, Bradley, \& Lesser, 2013; Lee, Choi, Kim, Nam, Kang, Koh, \& Oh, 2016).

Dari hasil tinjauan literatur yang peneliti lakukan, dapat disimpulkan bahwa resiliensi dapat dilihat sebagai proses, hasil, ataupun faktor protektif. Penelitian ini menggunakan sudut pandang resiliensi sebagai faktor protektif, yang menurut Madsen dan Abell (2010) dibentuk oleh 4 domain, yaitu pemecahan masalah, relasi 
suportif, optimisme, dan spiritualitas. Dengan demikian, signifikansi antara kedua variabel yang ditemukan dalam penelitian ini dapat dijelaskan dengan menggunakan konsep yang melibatkan keempat domain tersebut.

Menurut Madsen dan Abell (2010), pemecahan masalah mengacu pada kemampuan individu untuk menemukan solusi kreatif dalam mengatasi situasisituasi sulit. Sejumlah penelitian menemukan bahwa kemampuan individu dalam memecahkan masalah berkaitan dengan strategi coping individu. Strategi coping tersebut membantu individu dalam melakukan upaya kognitif dan menampilkan perilaku yang bermanfaat untuk menghadapi situasi-situasi menekan. Penelitian yang dilakukan oleh Demirbaş (2018) pada partisipan berupa mahasiswa yang mengalami trauma masa kanak-kanak menemukan bahwa individu yang mengalami peristiwa traumatis pada masa kanak-kanak memiliki kecenderungan untuk melakukan berbagai strategi coping. Salah satu strategi coping tersebut adalah strategi coping reflektif, yang lebih efektif untuk mengatasi masalah-masalah psikologis dibandingkan strategi coping lainnya. Hal ini menunjukkan bahwa domain pemecahan masalah merupakan aspek kognitif yang membantu penyintas kekerasan untuk melakukan coping yang efektif terhadap pengalaman kekerasan yang bersifat traumatis.

Selanjutnya adalah domain relasi suportif, yang merupakan domain sosiobehavioral dan mencakup kemampuan individu untuk menciptakan serta melestarikan relasi konstruktif yang resiprokal (Madsen \& Abell, 2010). Beberapa penelitian menemukan bahwa variabel dukungan sosial tidak dapat berkontribusi secara independen untuk mengurangi kemungkinan munculnya stres terkait trauma (Cheever \& Hardin, 1999; Benight \& Bandura, 2004). Penelitian-penelitian tersebut menemukan bahwa variabel dukungan sosial berfungsi dalam mengembangkan keyakinan mengenai efikasi diri individu untuk coping, yang pada akhirnya mempengaruhi kemunculan gejala-gejala PTSD. Dengan demikian, dapat disimpulkan bahwa relasi sosial yang positif mempengaruhi kepercayaan diri penyintas kekerasan untuk melakukan coping secara efektif.

Optimisme menjadi domain berikutnya pada konsep resiliensi trauma yang digunakan dalam penelitian ini. Menurut Madsen dan Abell (2010), optimisme merupakan energi kognitif-emosional terhadap ekspektasi positif yang dimiliki 
individu mengenai hidup dan hasil di masa mendatang. Sejumlah penelitian menemukan bahwa optimisme tidak dapat memprediksi kemunculan simtomsimtom pascatrauma secara independen pada individu-individu yang terpapar peristiwa traumatis (Cheever \& Hardin, 1999; Benight \& Bandura, 2004). Serupa dengan mekanisme yang terjadi pada variabel dukungan sosial, penelitianpenelitian tersebut menemukan bahwa optimisme dapat berkontribusi terhadap penurunan kemunculan simtom pascatrauma melalui pengembangan efikasi diri terkait kemampuan coping individu yang terpapar trauma. Dari penjelasan tersebut, terlihat adanya perbedaan antara domain relasi sosial yang mendukung dengan optimisme, meskipun keduanya sama-sama mempengaruhi efikasi diri terkait coping. Jika relasi sosial merupakan aspek optimisme merupakan aspek interindividual, maka optimisme bekerja sebagai aspek intra-individual yang mempengaruhi efikasi diri dalam melakukan coping yang efektif.

Domain terakhir adalah spiritualitas, yaitu domain yang muncul pada tahap refinement alat ukur yang dilakukan oleh Madsen dan Abell (2010) dan didefinisikan sebagai keyakinan personal yang dihayati secara mendalam dan dipraktikkan melampaui kegiatan-kegiatan yang bersifat duniawi. Acquaye (2017) mengemukakan bahwa individu yang terpapar peristiwa traumatis akan mencoba untuk memaknai peristiwa tersebut dengan menggunakan sumber daya yang tersedia, di mana salah satu sumber daya tersebut adalah spiritualitas. Manda (2015) mengemukakan bahwa spiritualitas membantu individu untuk menemukan makna, tujuan, dan harapan yang kemudian dapat membantu pemberdayaan diri pada individu yang mengalami peristiwa traumatis. Dengan kata lain, spiritualitas merupakan sumber daya individu dalam mengoptimalkan individu untuk mengatasi peristiwa traumatis secara konstruktif melalui relasi vertikal.

Berdasarkan uji beda yang dilakukan peneliti, terdapat beberapa temuan yang menarik, salah satunya adalah perbedaan resiliensi trauma jika ditinjau dari usia partisipan. Secara lebih spesifik, partisipan yang berusia 20-29 tahun memiliki resiliensi trauma yang lebih tinggi dibandingkan dengan partisipan yang berusia 30-40 tahun. Dalam studi literatur yang dilakukan oleh Burt dan Paysnick (2012), individu yang berusia 18-30 tahun umumnya dikategorikan dalam kelompok emerging adulthood. Studi tersebut menyimpulkan sejumlah faktor yang 
mendukung tingginya resiliensi pada kelompok tersebut, di antaranya adalah kemampuan kognitif yang telah berkembang serta penerimaan dukungan dari beragam jejaring sosialnya, seperti keluarga dan juga rekan-rekan di perguruan tinggi ataupun tempat kerja. Jika dikaitkan dengan konsep resiliensi trauma menurut Madsen dan Abell (2010), maka faktor-faktor tersebut berkaitan dengan domain pemecahan masalah dan relasi suportif yang berkontribusi terhadap pembentukan resiliensi trauma individu.

Temuan selanjutnya dari uji beda yang dilakukan adalah adanya perbedaan yang signifikan pada resiliensi trauma jika ditinjau dari keberadaan pasangan. Dalam penelitian ini, partisipan yang menikah memiliki resiliensi trauma yang lebih tinggi dibandingkan dengan individu yang belum menikah ataupun bercerai. Hal ini dapat dijelaskan dengan keberadaan pasangan yang dipersepsikan sebagai salah satu sumber dukungan yang relatif konstan dalam kehidupan partisipan. Studi yang dilakukan oleh Banyard dan Williams (2007) terkait resiliensi pada wanita dewasa yang merupakan penyintas kekerasan di masa kecil menemukan variabel dukungan sosial sebagai salah satu faktor protektif yang membantu partisipan menjadi resilien.

Terakhir, uji beda pada penelitian ini juga menemukan bahwa partisipan yang masih mengalami kekerasan memiliki tingkat PTSD yang lebih tinggi dibandingkan dengan partisipan yang sudah tidak lagi mengalami peristiwa kekerasan. Hasil tersebut dapat dikaitkan dengan keberlangsungan peristiwa kekerasan yang dipersepsikan sebagai stresor dan terus-menerus dihadapi oleh partisipan sehingga berdampak negatif terhadap kondisi psikologisnya. Selain itu, dengan belum berakhirnya peristiwa kekerasan yang dialami, maka partisipan tetap berhadapan dengan pelaku kekerasan, dan hal tersebut bersifat kontraproduktif dengan konsep pemulihan trauma. Dalam DSM-IV-TR, kejadian traumatik yang berlangsung secara persisten merupakan salah satu kriteria untuk menegakkan diagnosis PTSD (APA, 2000).

Salah satu kelemahan studi ini adalah penggunaan kuesioner yang tidak didukung oleh metode lain, seperti wawancara manual ataupun tes proyektif. Studi yang dilakukan oleh Wanderman (dalam Szwajca, 2014) menemukan bahwa hasil yang ditunjukkan oleh penggunaan metode-metode tersebut berbeda dengan hasil 
dari kuesioner lapor diri. Kelemahan lainnya adalah penelitian ini tidak menginvestigasi dampak kekerasan dalam lingkup spesifik, misalnya kekerasan seksual. Dengan demikian, hasil penelitian ini tidak dapat menjelaskan kekhasan sampel secara komprehensif.

\section{Kesimpulan dan Saran}

\section{Kesimpulan}

Hasil penelitian ini menemukan adanya hubungan negatif yang signifikan antara gejala PTSD dan resiliensi trauma pada partisipan berupa penyintas kekerasan yang berusia dewasa muda. Hal ini dapat dijelaskan oleh keterkaitan antara aspek personal dan sosial pada individu, sesuai dengan konstruk resiliensi trauma yang diangkat pada penelitian ini. Penelitian ini juga menemukan bahwa resiliensi trauma ditemukan lebih tinggi pada partisipan berusia 20-30 tahun serta pada partisipan yang menikah. Sementara itu, gejala PTSD ditemukan lebih rendah pada partisipan yang tidak lagi mengalami kekerasan.

\section{Saran}

Berdasarkan hasil penelitian ini, maka penting pagi praktisi psikologi klinis ataupun psikiater yang menangani penyintas kekerasan untuk memberikan intervensi yang bertujuan untuk mengoptimalisasi fungsi keempat domain yang membentuk resiliensi trauma sebagai upaya preventif pengembangan PTSD. Sejalan dengan hal tersebut, bagi praktisi kesehatan mental yang menangani penyintas kekerasan yang telah didiagnosis PTSD, maka intervensi yang diberikan dapat berorientasi pada penguatan keempat domain resiliensi trauma agar kondisi PTSD yang dialami tidak memburuk.

Saran lainnya terkait dengan pelaksanaan penelitian selanjutnya. Penelitian berikutnya yang juga dilakukan terkait konteks kekerasan, dapat mengombinasikan dua atau lebih metode pengambilan data, seperti kuesioner dengan wawancara ataupun dengan pengukuran psikofisiologis. Hal itu dapat dilakukan agar analisis data dapat dilakukan secara lebih mendalam. Penelitian berikutnya juga dapat menentukan kategori kekerasan secara lebih spesifik, agar dinamika dapat disajikan secara lebih komprehensif. 


\section{Daftar Pustaka}

Acquaye, H. E. (2017). PTSD, optimism, religious commitment, and growth as post-trauma trajectories: A structural equation modeling of former refugees. The Professional Counselor, 7 (4), 330 - 348. Diakses melalui http://tpcjournal.nbcc.org pada 10 Desember 2019

Agaibi, C. E. \& Wilson, J. P. (2005). Trauma, PTSD, and resilience: A review of the literature. Trauma, Violence, \& Abuse, 6 (3), 195 - 216. DOI: $10.1177 / 1524838005277438$

Amar, J. J. A. \& Otálvaro, L. E. O. (2012). Post traumatic stress disorder and adaptive capacity in victims of intimate partner violence. Psicología desde el Caribe, 29 (2). Diakses melalui scielo.org.co pada 28 November 2019

American Psychiatric Association. (2000). Diagnostic and Statistical Manual of Mental Disorders: DSM-IV-TR. Washington, DC: American Psychiatric Association.

Babcock, J. C., Roseman, A., Green, C. E., \& Ross, J. M. (2008). Intimate partner abuse and PTSD symptomology: Examining mediators and moderators of the abuse-trauma link. Journal of Family Psychology, 23, 295 - 302. DOI: $10.1037 / \mathrm{a} 0013808$.

Banyard, V. L., \& Williams, L. M. (2007). Women's voices on recovery: A multimethod study of the complexity of recovery from child sexual abuse. Child Abuse \& Neglect, 31(3), 275 - 290. doi:10.1016/j.chiabu.2006.02.016

Benight, C. C. \& Bandura, A. (2004). Social cognitive theory of posttraumatic recovery: The role of perceived self-efficacy. Behavior Research and Therapy, 42, 1129 - 1148. DOI: 10.1016/j.brat.2003.08.008

Bonanno, G.A. (2004) Loss, trauma, and human resilience: have we underestimated the human capacity to thrive after extremely aversive events? American Psychologist, 59 (1), 20-28. DOI: 10.1037/0003-066X.59.1.20

Burt, K. B., \& Paysnick, A. A. (2012). Resilience in the transition to adulthood. Development and Psychopathology, 24(02), 493-505. doi:10.1017/s0954579412000119

Cheever, K. H., \& Hardin, S. B. (1999). Effects of traumatic events, social support, and self-efficacy on adolescents' self-health assessments. Western Journal of Nursing Research, 21(5), 673-684. http://dx.doi.org/10.1177/01939459922044117

Connor, K. M. (2006). Assessment of resilience in the aftermath of trauma. J Clin Psychiatry, 67, 46-49. Diakses melalui http://www.repar.veille.qc.ca/infotcc/IMG/pdf/Connor_2006.pdf pada 21 November 2019 
Creamer, M., Burgess, P. \& McFarlane, A.C. (2001). Post-traumatic stress disorder: Findings from the Australian National Survey of Mental Health and Wellbeing. Psychol Med, 31 (7), 1237 - 1247. Diakses melalui https://digital.library.adelaide.edu.au/dspace/bitstream/2440/6593/1/hdl65 93.pdf pada 21 November 2019

Demirbaş, H. (2018). Examination of Problem Solving Skills Among University Students with Childhood Trauma Experiences. Kriz Dergisi, 26 (3), 1-1. Diakses melalui http://dergipark.gov.tr/kriz/issue/42041/485935 pada 5 Januari 2020

Ehrenreich, J. H. (2003). Understanding PTSD: Forgetting "trauma". Journal of Social Issues, 3 (1), 15 - 28. https://doi.org/10.1111/j.15302415.2003.00012.x

Ellison, L. \& Munro, V. E. (2017). Taking trauma seriously: Critical reflections on the criminal justice process. International Journal of Evidence and Proof, 21 (3), $183 \quad-\quad 208 . \quad$ Diakses melalui http://eprints.whiterose.ac.uk/100101/3/Taking\%20Trauma\%20Seriously $\% 20$ manuscript\%20(final).pdf pada 21 November 2019

Gillikin, C., Habib, L., Evces, M., Bradley, B., Ressler, K. J. \& Sanders, J. (2016). Trauma exposure and PTSD symptoms associate with violence in inner city civilians. J. Psychiatr Res, 83, 1 - 7. J Psychiatr Res, 83, 1 - 7. DOI 10.1016/j.jpsychires.2016.07.027.

Haddadi, P. \& Besharat, M. A. (2010). Resilience, vulnerability, and mental health. Procedia Social and Behavioral Sciences, 5, 639 - 642. doi:10.1016/j.sbspro.2010.07.157

Hyland, P., Mark, S., Hansen, M., Vallières, F., Murphy, J., \& Elklit, A. (2016). The temporal relations of PTSD symptoms among treatment-seeking victims of sexual assault: A longitudinal study. Journal of Loss and Trauma, 21 (6), 492-506. DOI: 10.1080/15325024.2015.1117933

Kumar, R. (2011). Research Methodology: A Step-by-step Guide for Beginners 3rd Edition. Singapore: SAGE Publications Asia-Pacific Pte Ltd.

Lee, J. K., Choi, H. G., Kim, J. Y., Nam, J., Kang, H. T., Koh, S. B., \& Oh, S. S. (2016). Self-resilience as a protective factor against development of posttraumatic stress disorder symptoms in police officers. Ann Occup Environ Med, 28, 58. doi: 10.1186/s40557-016-0145-9 
Madsen, M. D. \& Abell, N. (2010). Trauma resilience scale: Validation of protective factors associated with adaptation following violence. Research on Social Work Practice, 20 (2), 223 - 233. https://doi.org/10.1177/1049731509347853

Magezi, V. \& Manda, C. (2016). The use of spiritual resources to cope with trauma in daily existence. In die Skriflig, 50 (1). https://doi.org/10.4102/ids.v50i1.2145

Manda, C.B. (2015). Re-authoring life narratives of trauma survivors: Spiritual perspective. HTS Teologiese Studies/Theological Studies, 71(2). http://dx.doi.org/10.4102/ hts.v71i2.2621

Nathanson, A. M., Shorey, R. C., Tirone, V., \& Rhatigan, D. L. (2012). The prevalence of mental health disorders in a community sample of female victims of intimate partner violence. Partner Abuse, 3 (1), 59 - 75. DOI: $10.1891 / 1946-6560.3 .1 .59$

Papalia, E. D. \& Feldman, R. T. (2014). Menyelami Perkembangan Manusia. Jakarta: Salemba Humanika.

Reckdenwald, A., Mancini, C., \& Beauregard, E. (2013). The cycle of violence: Examining the impact of maltreatment early in life on adult offending. Violence and Victims, 28 (3), $466-482$.

Smith, C. \& Thornberry, T. P. (1995). The relationship between childhood maltreatment and adolescent involvement in delinquency. Criminology, 33 (4).

Ssenyonga, J., Owens, V., \& Olema, D. K. (2012). Posttraumatic growth, resilience, and posttraumatic stress disorder among refugees. Procedia Social and Behavioral Sciences, 82, 144 - 148. doi:10.1016/j.sbspro.2013.06.238

Szwajca, K. (2014). Resilience and responses to the experience of trauma: A fascinating but difficult study area. Psychiatr. Pol., 48 (3), 563 - 572. Diakses melalui https://pdfs.semanticscholar.org/d2e9/e4452cc51ccc97a99d3106f9b39a4c 6ca3a3.pdf pada 21 November 2019

Weathers, F. W., Litz, B. T., Herman, D. S., Huska, J. A. \& Keane, T. M. (1993). The PTSD checklist: Reliability, validity, and diagnostic utility. Paper presented at the $9^{\text {th }}$ Annual Convention of the International Society for Traumatic Stress Studies, San Antonio, TX. 
Wrenn, G. L., Wingo, A. P., Moore, R., Pelletier, T., Gutman, A. R., Bradley, B., \& Ressler, K. J. (2011). The effect of resilience on posttraumatic stress disorder in trauma-exposed inner-city primary care patients. Journal of the National Medical Association, 103 (7), 560 - 566. doi: 10.1016/s00279684(15)30381-3

Zingraff, M. T., Leiter, J. Myers, K. A. \& Johnsen, M. C. (1993). Child maltreatment and youthful problem behavior. Criminology, 31 (2).hate crime. Safer Communities 7 2, 24-35. 